\title{
Nanostructured Layers for Catalytic Applications
}

\author{
M. R. Bayati, ${ }^{1}$ A. Kajbafvala, ${ }^{1}$ P. Sangpour, ${ }^{2}$ and H. R. Zargar $^{3}$ \\ ${ }^{1}$ Department of Materials Science and Engineering, North Carolina State University, Raleigh, NC 27695, USA \\ ${ }^{2}$ Materials and Energy Research Center, Tehran 19839, Iran \\ ${ }^{3}$ Department of Metals and Materials Engineering, The University of British Columbia, Vancouver BC, Canada V6T $1 Z 4$ \\ Correspondence should be addressed to M. R. Bayati, bayati@iust.ac.ir
}

Received 5 October 2011; Accepted 5 October 2011

Copyright ( $) 2012$ M. R. Bayati et al. This is an open access article distributed under the Creative Commons Attribution License, which permits unrestricted use, distribution, and reproduction in any medium, provided the original work is properly cited.

Higher energy consumption, which is a result of increasing the world population, gives rise to decreasing in fossil fuel reserves and creating environmental pollutions. Pollution is the introduction of contaminants into a natural environment that causes instability, disorder, harm, or discomfort to the ecosystem and can take the form of chemical substances or energy, such as noise, heat, or light. Remediation of the environmental pollutants is necessary. Since now three decades, advanced oxidation technologies "in particular photocatalysis" gained much attention by scientifics. In their point of view, to counter environmental pollutions, a simple and comprehensive photonic reaction system which converts the solar energy into the chemical energy of a redox system, namely, photocatalysis, would be helpful for the detoxification processes. Nowadays, heterogeneous photocatalysis is the most efficient method for destroying organic pollutants in especially aqueous media. This process is based on the use of ultraviolet or visible radiations to excite a semiconductor on whose surface the oxidation of the pollutants is performed. This special issue addresses advances in nanostructured layers for photocatalytic applications.

In the first paper of this special issue, $\mathrm{ZnO}$ nanoparticles were deposited on $\mathrm{Si}, \mathrm{Si} / \mathrm{Au}$, and $\mathrm{Si} / \mathrm{Au} / \mathrm{ZnO}$ substrates by mist atomization, and effect of the substrates conditions on the structural, morphological, and photoluminescence properties of the nanoparticles was investigated. It was found that crystallite size and lattice strain were significantly affected by substrate surface type and temperature. Smallest crystallite size was obtained on $\mathrm{Si} / \mathrm{Au} / \mathrm{ZnO}$ at $400^{\circ} \mathrm{C}$. The second paper deals with effect of $\mathrm{Ti}^{3+}$ on photocatalytic efficiency of titanium dioxide. The authors revealed that physical and chemical properties of $\mathrm{TiO}_{2}$ were dominantly determined by its surface condition and especially presence of
$\mathrm{Ti}^{3+}$ species on its surface. A formation mechanism for the aforementioned defect was also proposed in this paper. Various generation methods for $\mathrm{Ti}^{3+}$ surface defect as well as its effect on optical and photocatalytic properties were discussed. It was shown that a detailed picture of $\mathrm{Ti}^{3+}$ surface defects would help to understand reactivity and overall material performance in photocatalytic applications. Ag$\mathrm{Cu}$ bimetallic catalysts were prepared by microemulsion method, and their catalytic performance in epoxidation of styrene was evaluated in the third paper of this special issue. In this study, deposition of $\mathrm{Ag}$-Cu bimetallic nanoparticles by the coreduction of $\mathrm{Ag}^{+}$and $\mathrm{Cu}^{2+}$ cations with $\mathrm{N}_{2} \mathrm{H}_{4} \cdot \mathrm{H}_{2} \mathrm{O}$ as reductant on reticulate-like $\gamma$-alumina particles was studied. $\mathrm{Ag}-\mathrm{Cu}$ bimetallic nanoparticles supported by $\gamma$-alumina showed better catalytic activity on the epoxidation of styrene as compared with the corresponding monometallic silver or copper catalysts. Herein, these could also be promising candidates for applications in many other reactions, namely, $\mathrm{CO}$ oxidation. In the next paper, porous diatomite immobilized $\mathrm{Cu}-\mathrm{Ni}$ bimetallic nanocatalysts for direct synthesis of dimethyl carbonate. Upon various characterizations, it was shown that the bimetallic composite is effectively alloyed and well immobilized inside or outside the structural pores. In addition, the authors showed that existence of electronrich and electron-deficient centers is resulted from the strong interaction of diatomite with $\mathrm{Cu}-\mathrm{Ni}$, and the synergy of $\mathrm{Cu}-\mathrm{Ni}$ alloy may be responsible for the high performance of this catalyst. Fabrication of photofunctional nanoporous alumina membrane (PNAM) and its photoinactivation effect of vesicular stomatitis virus were reported in the fifth paper. To open the possibility for its environmental application, PNAM was applied for the removal of a virus without rendering cytotoxicity to the cells in vitro. The authors concluded 
with the complete suppression of plaque-forming ability of vesicular stomatitis virus (VSV) by PNAM-mediated PACT (photodynamic antimicrobial chemotherapy). In the next paper entitled "the physical properties of erbium-doped yttrium iron garnet films prepared by sol-gel method" thin films of $\mathrm{Er}_{x} \mathrm{Y}_{3-x} \mathrm{Fe}_{5} \mathrm{O}_{12}$ were deposited through sol-gel method. These crystalline films were found to be soft magnetic materials. The saturation magnetization is reduced with Er substitution because the magnetic moments of $\mathrm{Er}^{3+}$ ions coupled antiferromagnetically to the effective moment formed by $\mathrm{Fe}^{3+}$ ions. The maximum coercivity was obtained at $x=1.2$. In the next paper, a decrease in $\mathrm{NiO}-\mathrm{MgO}$ phase through its solid solution equilibrium with tetragonal $\left(\mathrm{La}_{1-z} \mathrm{Sr}_{z}\right) 2 \mathrm{Ni}_{1-y} \mathrm{Mg}_{y} \mathrm{O}_{4-\delta}$ and its effect on catalytic partial oxidation of methane were investigated. The main concept of this study is utilizing the solid-state reaction equilibrium between the two solid solutions: the rock salt $\mathrm{NiO}-\mathrm{MgO}$ and the tetragonal $\left(\mathrm{La}_{1-z} \mathrm{Sr}_{z}\right) 2 \mathrm{Ni}_{1-y} \mathrm{Mg}_{y} \mathrm{O}_{4-\delta}$ (LSNM) phase in order to reduce the size of $\mathrm{NiO}-\mathrm{MgO}$. This size reduction aimed to improve the coke resistance of the $\mathrm{Ni}^{0}$ catalyst in the partial oxidation of methane (POM) without compromising the activity of catalyst. In the eighth paper, catalytic activity of $\mathrm{ZrO}_{2}$ nanotube arrays prepared by anodizing method was studied, where nanotubes were prepared in aqueous electrolyte containing $\left(\mathrm{NH}_{4}\right)_{2} \mathrm{SO}_{4}$ and $\mathrm{NH}_{4} \mathrm{~F}$. Calcination temperature and electrolyte concentration have a great influence on catalytic activity. Results indicate that nanotube arrays have highest catalytic activity when the concentration of $\left(\mathrm{NH}_{4}\right)_{2} \mathrm{SO}_{4}$ is $1 \mathrm{~mol} / \mathrm{L}$, the concentration of $\mathrm{NH}_{4} \mathrm{~F}$ is $1 \mathrm{wt} \%$, and the calcination temperature is $400^{\circ} \mathrm{C}$. Finally, modification of clays by sol-gel reaction and their use in the ethylene in situ polymerization for obtaining nanocomposites was reported. It was given away that the catalytic activity significantly increases when the clays were modified via solgel reaction under acidic or basic conditions compared with neutral condition.

M. R. Bayati

A. Kajbafvala

P. Sangpour

H. R. Zargar 

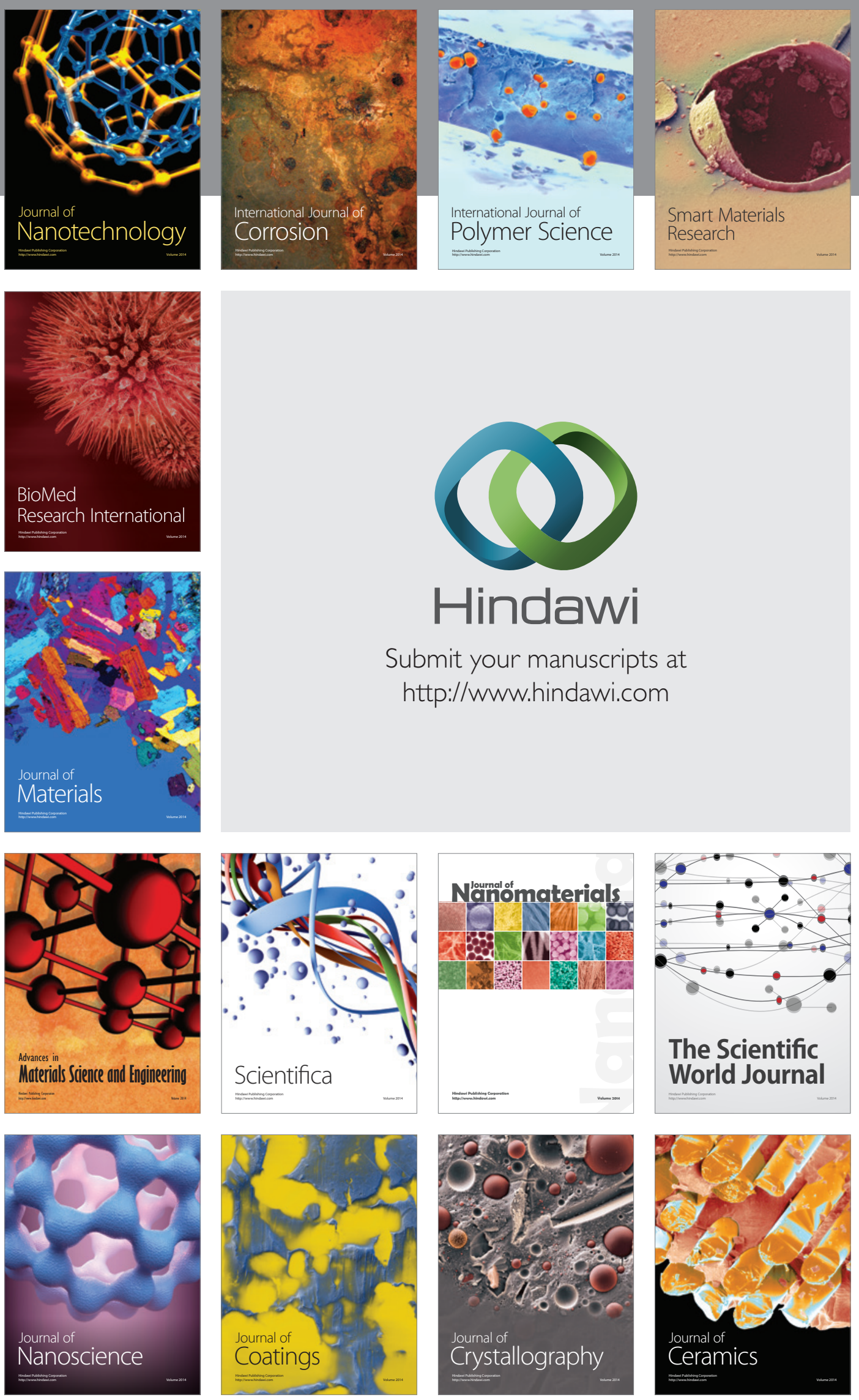

The Scientific World Journal

Submit your manuscripts at

http://www.hindawi.com

\section{World Journal}

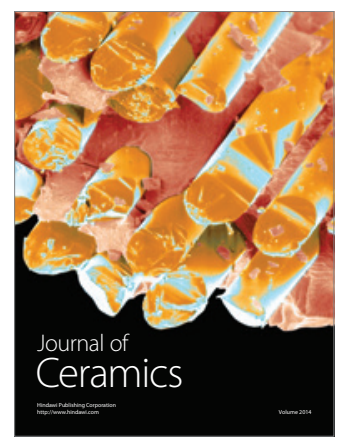

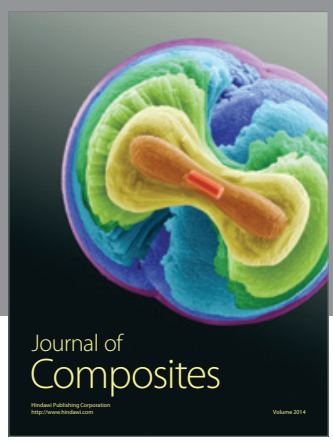
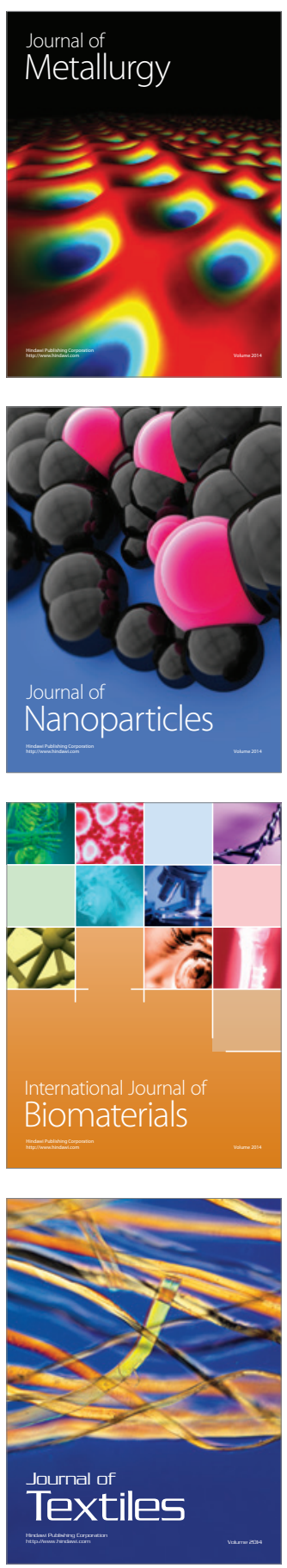